\title{
SUPERAÇÃO DE DORMÊNCIA EM Brachiaria humidicola COM ÁCIDO SULFÚRICO EM DIFERENTES ESTÁGIOS DE ARMAZENAMENTO
}

\author{
Alline Mendes Alves ${ }^{1}$, Thadeu Henrique Novais Spósito ${ }^{2}$, Fernando Bernardo Martins ${ }^{1}$, Luis \\ Eduardo Vieira Pinto ${ }^{1}$, Lorrayne Guimarães Bavaresco ${ }^{1}$, Rodrigo Bernardo Soldá ${ }^{3}$, Felipe Silva \\ Loosli $^{1}$, Patrícia Rafaella de Mello ${ }^{1}$, Wilton Felipe Teixeira ${ }^{1}$ \\ ${ }^{1}$ Universidade do Oeste Paulista - UNOESTE, Programa de Pós-Graduação em Agronomia, Presidente Prudente, SP. \\ 'Universidade Estadual Paulista "Júlio de Mesquita Filho", Programa de Pós-Graduação em Agronomia, Ilha Solteira, \\ SP. \\ ${ }^{3}$ Universidade do Oeste Paulista - UNOESTE, Programa de Residência Presidente Prudente, SP. \\ E-mail: alinemendesflor@yahoo.com.br
}

\section{RESUMO}

A dormência nas sementes é um fenômeno que provém da adaptação das espécies às condições ambientais. Em sementes de forrageiras esse fenômeno está especialmente presente. Encontrar formas de superar essa dormência, otimizar a germinação de sementes e aprimorar o estabelecimento dos pastos tem sido cada vez mais um desafio para os pesquisadores. 0 objetivo desse estudo foi avaliar o efeito da escarificação com ácido sulfúrico concentrado à $98 \%$ sobre a germinação de sementes de duas diferentes safras. $O$ delineamento experimental utilizado foi blocos casualizados, contendo 4 tratamentos (controle, 3, 4 e 5 minutos), com 6 repetições de 25 sementes cada, totalizando 150 sementes por tratamento. De maneira geral a escarificação a um curto período de tempo foi mais eficiente para sementes com maior tempo de armazenamento e o tratamento de 3 minutos apresentou uma maior porcentagem de germinação para ambas as safras.

Palavras-chave: sementes, forrageiras, germinação

\section{BREAK OF DORMANCY IN Brachiaria humidicola FOR SULFURIC ACID IN DIFFERENT AGES OF STORAGE}

\begin{abstract}
Seed dormancy is a phenomenon that comes from adapting species to environmental conditions. In forage seeds this phenomenon is especially present. Finding ways to overcome this dormancy, optimize seed germination and improve pasture establishment has been increasingly challenging for researchers. The objective of this study was to evaluate the effect of scarification with $98 \%$ concentrated sulfuric acid on seed germination of two different crops. The experimental design was randomized blocks, containing 4 treatments (control, 3, 4 and 5 minutes), with 6 replicates of 25 seeds each, totaling 150 seeds per treatment. In general, scarification over a short period of time was more efficient for seeds with longer storage times and the 3 minute treatment showed a higher percentage of germination for both crops.
\end{abstract}

Keywords: seeds, forage, germination

\section{INTRODUÇÃO}

A pecuária no Brasil, em geral, se baseia em sistemas que usam a pastagem como a principal fonte de alimento para o gado, em geral essas pastagens estão localizadas em áreas de solo ácido e de baixa fertilidade. Para essas condições as espécies do gênero Brachiaria tem sido 
bastante utilizadas, pois apresentam boa tolerância a alto teor de Al e baixos teores de $\mathrm{P}$ e Ca no solo (ALVIM et al., 2002).

O país é o maior produtor, consumidor e exportador de sementes de espécies forrageiras tropicais, com produção estimada de 70 mil toneladas, na safra 2008/2009 (ABRASEM, 2011), tendo alcançado produções superiores a 100 mil toneladas em safras anteriores. Mais de $80 \%$ do mercado é dominado por cultivares do gênero Brachiaria, graças à ampla adaptação das espécies às condições edafoclimáticas das regiões, sobretudo aos solos ácidos e de baixa fertilidade predominantes nos trópicos (RAO et al., 2011).

Nas duas últimas décadas tem sido notável o aumento da área e pastagens formadas com gramíneas do gênero Brachiaria, acompanhado de um aumento proporcional na produção e comercialização de suas sementes (MARTINS et al., 1998). O gênero Brachiaria conta com cerca de 80 espécies, na grande maioria de origem africana, as cinco principais espécies do gênero cultivadas no país são em ordem decrescente, $B$. decumbens, $B$. brizantha, $B$. humidicola, $B$. ruziziensis e $B$. dictyoneura (ALVIM et al., 2002).

Brachiaria humidicola é uma espécie muito eficiente na proteção do solo, contra a erosão por produzir grande quantidade de estolões que se enraízam quando em contato com o solo. É uma das poucas espécies de forrageiras disponíveis que se adaptam a solos mal drenados sujeitos a inundações (ALVIM et al., 2002). A propagação é feita principalmente por sementes. Sob manejo intensivo (adubações, pastejo rotativo, irrigação, etc) essa forrageira pode produzir mais de 30 t/ha/ano de matéria seca, produção esta, obtida na época das chuvas, uma vez que ela apresenta baixa resistência à seca.

Para que o mercado de sementes seja cada vez mais sólido e a qualidade dos pastos cada vez mais alta já vem sendo estudado por pesquisadores a dormência que afeta as sementes de forrageiras tropicais. Estudos relacionados a resposta de sementes de $B$. humidicola a diferentes tratamentos para superação da dormência têm apresentado resultados contraditórios e inconclusivos. Para alguns autores, a escarificação de sementes recém colhidas auxilia na redução da intensidade de dormência (OLIVEIRA e MASTROCOLA, 1983). Para outros, a escarificação ácida é prejudicial à qualidade fisiológica das sementes, não sendo recomendada (ATALLA e TOSELLO 1979; RODRIGUES et al., 1986; MACEDO et al., 1994; USBERTI e MARTINS 2007).

Para Brachiaria, são relatados dois tipos de dormência, a dormência associada ao embrião, e a imposta pelos envoltórios, que persistiria em sementes armazenadas por longos períodos (SIMPSON, 1990). A dormência do embrião seria superada ao longo do armazenamento, restando apenas à imposta pelos envoltórios, que pode ser superada por meio do método de escarificação química com ácido sulfúrico, conforme as Regras para Análise de Sementes (BRASIL, 2009).

Visto que a formação de pastagens através de semeadura da gramínea $B$. humidicola geralmente é um processo tardio devido a dormência das sementes este trabalho teve como objetivo avaliar a taxa de germinação das sementes de diferentes safras submetidas a diferentes tempos de tratamento para superação da dormência utilizando ácido sulfúrico.

\section{METODOLOGIA}

Este estudo foi desenvolvido no Laboratório de Química e Sementes da Escola Técnica Estadual Professor Dr. Antônio Eufrásio de Toledo e no Viveiro Florestal de Mudas de Presidente Prudente/SP, no período de julho a setembro de 2016. O clima da região pela classificação de Köppen é caracterizado como Tropical Aw, com estação chuvosa no verão e inverno seco. Foram avaliados dois lotes de sementes de Brachiaria humidicola, sendo o lote 1 correspondente a safra 2014/2015 e o lote 2 a safra 2015/2016 disponibilizadas pela Associação Nacional dos Produtores de Sementes (Amprosem). 
Para os tratamentos com escarificação, as sementes forma imersas em $20 \mathrm{ml}$ de solução de ácido sulfúrico concentrado (98\%), com agitação constante, em períodos de tempo prédeterminados para cada tratamento. Após este procedimento, as sementes foram lavadas em água corrente com o auxílio de peneira por três minutos e o excesso de água foi retirado superficialmente com papel toalha (BRASIL 2009). Posteriormente foi realizada manualmente a remoção de todas as estruturas de cobertura das sementes (glumas, lemas e páleas).

Para avaliação de emergência de plântulas foram semeadas 25 sementes/repetição, a $1 \mathrm{~cm}$ de profundidade em tubetes contendo substrato de fibra de coco sem adição de nutrientes. Os tubetes foram acondicionados em viveiro de mudas em ambiente aberto, com irrigação por aspersão, acionada três vezes ao dia.

A taxa (\%) de emergência de plântulas foram determinadas pela contagem de plântulas emersas, considerando a parte área visível acima da superfície do substrato, aos 7, 14 e 21 dias após a semeadura. $O$ índice de velocidade de emergência (IVE) foi calculado a partir dos resultados obtidos durante a realização do teste de emergência de plântulas, utilizando a equação descrita por Maguire (1962).

Os dados obtidos foram submetidos à análise de variância e as médias submetidas ao teste de Turkey a $5 \%$ de probabilidade para verificação de significância. A avaliação estatística do experimento foi realizada através do software SISVAR Sistema para Análise de Variância (FERREIRA, 2011).

\section{RESULTADOS}

Na média geral para os dois lotes os maiores valores de taxa de emergência foram observados na escarificação de 3 minutos (tratamento 2) e os resultados menos expressivos ocorreram no tratamento controle onde não houve nenhum contato com o ácido sulfúrico. Para o lote 1 as sementes imersas em ácido sulfúrico por 4 e 5 minutos não apresentaram diferença significativa dos demais tratamentos na análise das taxas médias de emergência (Tabela 1). No lote 2 os maiores valores de emergência também foram encontrados no tratamento 2 ( $3 \mathrm{~min}$ ) no entanto, este diferiu estatisticamente apenas do tratamento 5 que obteve a menor valor.

O lote 2, com sementes mais jovens, apresentou em geral, taxa de emergência (5,58\%) estatisticamente menor em relação ao observado para o lote 1, que apresentou porcentagem média de 10,66 para emergência de plântulas.

Tabela 1. Taxas médias de emergência de plântula de B. humidicola em diferentes tempos de escarificação em ácido sulfúrico.

\begin{tabular}{lcccc}
\hline \multirow{2}{*}{ Tratamento } & \multicolumn{5}{c}{ Tempo de imersão em ácido sulfúrico (min) } \\
\cline { 2 - 5 } & 0 & 3 & 4 & 5 \\
\cline { 2 - 5 } Lote 1 & $5 \mathrm{bA}$ & $18,6 \mathrm{aA}$ & $9,5 \mathrm{abA}$ & $9,6 \mathrm{abA}$ \\
Lote 2 & $2.5 \mathrm{abA}$ & $11.5 \mathrm{aA}$ & $6,6 \mathrm{abA}$ & $1,6 \mathrm{bB}$ \\
Lote 1 x Lote 2 & $3,7 \mathrm{~b}$ & $15 \mathrm{a}$ & $\mathbf{8 a b}$ & $5,6 \mathrm{~b}$ \\
\hline
\end{tabular}

Médias seguidas de letras minúsculas distintas, na coluna, e maiúscula na linha, diferem estatisticamente entre si pelo teste de Turkey à $5 \%$ de probabilidade.

\section{DISCUSSÃO}


No presente experimento, a escarificação ácida mostrou-se mais eficiente na indução da germinação e emergência das sementes mais velhas (lote 1 ) em relação às com menor tempo de armazenamento (lote 2). Alguns trabalhos têm demonstrado que a dormência em sementes de gramíneas forrageiras é mais acentuada em sementes recém-colhidas, o que pode explicar o maior efeito da escarificação sobre a germinação de sementes mais velhas. A pós-maturação é um método comum usado para superação da dormência em sementes recém-colhidas e consiste em um período de vários meses de armazenamento seco em temperatura ambiente (METZGER, 2003). No entanto, os 22 mecanismos do processo de pós-maturação associados com o comportamento das sementes ainda é um fenômeno mal compreendido, apesar de várias publicações terem começado a revelar novas informações importantes sobre este processo (CADMAN et al., 2006; CHIBANI et al., 2006; ORACZ et al., 2007; CARRERA et al., 2008).

Possivelmente o armazenamento foi determinante para a superação da dormência em $B$. humidícola assim como foi constatado por Renard e Capelle (1976) em B. ruziziensis, Martins et al. (1998), Vieira et al. (1998) e Câmara e Seraphin (2002) em B. brizantha cv. Marandu e Costa et al. (2011) em B. humidicola. Gonzalez et al. (1993) afirmaram que as condições de armazenamento tiveram efeito significativo sobre a germinação porque $B$. decumbens exibiu dormência póscolheita que podia ser reduzida por armazenamento, sob condições ambientes por 6 meses ou controladas por 12 a 16 meses. Um estudo com 9 espécies de Brachiaria, mostrou que, apenas o armazenamento não foi suficiente para quebrar a dormência, pois a escarificação com ácido sulfúrico aumentou a germinação de sementes armazenadas, por 11 meses (Brachiaria decumbens) e por 14 meses (Brachiaria dictyoneura) (RUIZ et al. 1996).

Quanto aos tratamentos o que apresentou valores mais altos de germinação foi o de 3 minutos para ambos os lotes, sendo 18,6\% para o lote 1 e 11,5 para o lote 2. Custódio (2000), trabalhando com lotes de $B$. humidicola com diferentes períodos de armazenamento encontrou diferenças principalmente no tratamento com ácido sulfúrico por 5 minutos (tratamentos com 0 , 5, 10, e $15 \mathrm{~min}$ ) onde o tratamento com ácido sulfúrico foi efetivo no aumento da germinação. Por outro lado quanto maior o período de tratamento com ácido sulfúrico maior foi a perda de germinação, mostrando que o tratamento ácido apresenta uma relação negativa com a germinação das sementes desta espécie.

Resultados negativos com ácido sulfúrico para $B$. humidicola também foram obtidos por diversos autores (Atalla \& Tosello, 1979; Oliveira \& Mastrocola, 1983; Macedo et al., 1994; Faria et al., 1996; Ruiz et al., 1996). Custódio (2000), encontrou resposta negativa para a utilização do tratamento com ácido sulfúrico em $B$. humidicola com 6 meses de armazenamento e resposta positiva para a utilização de ácido sulfúrico, isolado, por 10 minutos, apenas após o armazenamento, por 8 meses, das sementes tratadas. A B. humidicola mostrou resposta negativa ao tratamento com ácido sulfúrico em todas as avaliações utilizando armazenamento de sementes intactas.

Usberti \& Martins (2007), embora não tenham observado efeitos positivos da escarificação ácida em sementes de $B$. humidicola, ressaltaram que este tratamento pode simular a ação do fogo, empregado para renovação de pastagens, em razão do seu efeito dessecante e das altas temperaturas geradas após sua aplicação nas sementes, o que favoreceria maior absorção de água e difusão de oxigênio. A escarificação ácida também foi considerada, por Almeida \& Silva (2004), como alternativa para redução da dormência de sementes de $B$. humidicola cv. Llanero.

Apesar de as Regras para Análise de Sementes (BRASIL, 2009) recomendar a escarificação química para $B$. humidicola com ácido sulfúrico concentrado $\left(\mathrm{H}_{2} \mathrm{SO}_{4}\right)$ de no máximo 10 minutos. Outros trabalhos demonstraram que a escarificação com ácido sulfúrico concentrado acima de 5 minutos pode ser prejudicial para a qualidade fisiológica das sementes (CUSTÓDIO, 2000). Este 
trabalho demonstrou ligeiramente que a escarificação ácida em um curto período de tempo pode auxiliar na quebra de dormência de sementes armazenadas de B. humidicola. Ainda são necessários mais testes quanto ao tempo de escarificação e a concentração do ácido sulfúrico para determinar o tratamento que melhor se adapte ao longo do armazenamento.

\section{CONCLUSÃO}

A escarificação com ácido sulfúrico por um curto período de tempo foi efetiva para potencializar os mecanismos de superação de dormência de sementes com maior período de armazenamento. Outros estudos ainda são necessários para o ajuste perfeito das concentrações e períodos de tempo para escarificação com $\mathrm{H}_{2} \mathrm{SO}_{4}$ para essa espécie.

\section{REFERÊNCIAS}

ABRASEM. JOSÉ, M. R. Brachiaria humidicola: uma abordagem. Brasília, DF: ABRASEM UNIPASTO;, 2011. Anuário. Disponível em: http://www.unipasto.com.br/noticia individual.php?id=36 Acesso em: 06 maio 2017.

ALMEIDA, C.R.; SILVA, W.R. Comportamento da dormência em sementes de Brachiaria dictyoneura cv. Llanero submetidas às ações do calor e do ácido sulfúrico. Revista Brasileira de Sementes, v.26, n.1, 2004. http://dx.doi.org/10.1590/S0101-31222004000100007

ALVIM, M. J.; BOTREL, M. A.; XAVIER, D. F. As principais espécies de Brachiaria utilizadas no país. Comunicado Técnico 22. Ministério da Agricultura Pecuária e Abastecimento. Embrapa - Juiz de Fora, MG. Dez, 2002.

ATALLA, A. M. P.; TOSELLO, J. Observações sobre dormência em duas espécies de Brachiaria: $B$. decumbens e $B$. humidicola em condições de laboratório. Científica, v. 7, n. 3, p. 353-355, 1979.

BRASIL, Ministério da Agricultura Pecuária e Abastecimento. Regras para análise de Sementes. Brasília: SNDA/DNDV/CLV, 399p. 2009.

CADMAN, C. S. C., TOOROP, P. E., HILHORST, H. W. M., FINCH-SAVAGE, W. E. Gene expression profiles of Arabidopsis seeds during dormancy cycling indicate a common underlying dormancy control mechanism. Plant Journal, Oxford, v. 46, p. 805-822, 2006. https://doi.org/10.1111/i.1365$\underline{313 X .2006 .02738 . x}$

CÂMARA, H. H. L. L.; STACCIARINI-SERAPHIN, E. Germinação de sementes de Brachiaria brizantha cv. Marandu sob diferentes períodos de armazenamento e tratamento hormonal. Pesquisa Agropecuária Tropical, Goiânia, v. 32, n. 1, p. 21-28, 2002.

CARRERA, E.; HOLMAN, T.; MEDHURST, A.; DIETRICH, D.; FOOTITT, S.; THEODOULOU, F. L.; HOLDSWORTH, M. J. Seed after-ripening is a discrete developmental pathway associated with specific gene networks in Arabidopsis. Plant Journal, Oxford, v. 53, p. 214-224, 2008. https://doi.org/10.1111/i.1365-313X.2007.03331.x 
CHIBANI, K.; ALI-RACHEDI, S.; JOB, C.; JOB, D.; JULLIEN, M.; GRAPPIN, P. Proteomic analysis of seed dormancy in Arabidopsis. Plant Physiology, Minneapolis, v.142, p. 1493-1510. 2006. https://doi.org/10.1104/pp.106.087452

COSTA, C. J.; ARAÚJO, R. B.; VILLAS BÔAS H. D. C. Tratamentos para a superação de dormência em sementes de Brachiaria humidicola (Rendle) Schweick. Pesquisa Agropecuária Tropical, Goiânia, v. 41, n. 4, p. 519-524, 2011. https://doi.org/10.5216/pat.v41i4.15100

CUSTÓDIO, C. C. Efeito do ácido sulfúrico concentrado sobre o potencial fisiológico de sementes de Brachiaria brizantha (A. Rich) Sapf cv. 'Marandu' e Brachiaria humidicola (Rendle) Schweick. cv. 'Tully' durante o armazenamento. 2000. 203 f. Tese (Doutorado em Ciências Biológicas). Universidade Estadual Paulista, Rio Claro, 2000.

FARIA, J.; GARCIA-AGUILAR, L.; GONZALEZ, B. Efecto de métodos químicos de escarificación sobre la germinación de seis gramíneas forrajeras tropicales. Revista de la Faculdade Agronomia, Universidad del Zulia, v. 13, n. 4, p. 387-393, 1996.

FERREIRA, D. F. Sisvar: a computer statistical analysis system. Ciência \& Agrotecnologia, Lavras, v. 35, n. 6, p. 1039-1042, nov./dez., 2011.

GONZALEZ, Y.; MENDOZA, F.; TORRES, R. Efecto del almacenamiento y la variacion de temperatura sobre las semillas de Brachiaria decumbens cv. 'Basilisk'. Pastos y Forrajes, v. 16, n. 2, p. 155-165, 1993.

MACEDO, E. C.; GROTH, D.; LAGO, A. A. do. Efeito de escarificação com ácido sulfúrico na germinação de sementes de Brachiaria humidicola (Rendle) Schweick. Pesquisa Agropecuária Brasileira, v. 29, n. 3, p. 455-460, 1994.

MARTINS, L.; LAGO, A. A. do; GROTH, D. Valor cultural de sementes de Brachiaria brizantha (Hochst. ex A. rich) Stapf durante o armazenamento. Revista Brasileira de Sementes, Brasília, v. 20, n. 1, p. 60-64, 1998. https://doi.org/10.17801/0101-3122/rbs.v20n1p60-64

METZGER, G. L. Functions and regulation of $\beta-1,3$-glucanase during seed germination, dormancy release and after-ripening. Seed Science Research, Wallingford, v. 13, p. 17-34, 2003. https://doi.org/10.1079/SSR2002121

OLIVEIRA, P. R. P. de; MASTROCOLA, M. A. Brachiaria humidicola (Rendle) Schweickerdt: viabilidade de suas sementes. Boletim de Industria Animal, v. 40, n. 1, p. 49-53, 1983.

ORACZ, K.; BOUTEAU, H. E. M.; FARRANT, J. M.; COOPER, K.; BELGHAZI, M.; JOB, C.; JOB, D.; CORBINEAU, F.; BAILLY, C. ROS production and protein oxidation as a novel mechanism for seed dormancy alleviation. Plant Journal, Oxford, v. 50, p. 452-465, 2007. https://doi.org/10.1111/j.1365-313X.2007.03063.x

RAO, I. M.; KERRIDGE, P. C.; MACEDO, M. C. M. Nutritional requirements of Brachiaria and adaptation to acid soils. In: MILES, J. W., MAASS, B. L.; VALLE, C. B. do. Brachiaria: biology, agronomy, and improvement. (Ed.) Cali: CIAT - EMBRAPA/CNPGC, p. 53-71. 1996. 
RENARD, C.; CAPELLE, P. Seed germination in Ruzizi grass (Brachiaria ruziziensis Germain \& Evrard). Australian Journal of Botany, Melbourne, v. 24, n. 4, p. 437-446, 1976. https://doi.org/10.1071/BT9760437

RODRIGUES, J. D.; DELACHIAVE, M.H.A.; RODRIGUES, S.D.; PEDRAS, J. F.; GAETI, O. B. N. Efeitos de diferentes métodos para a quebra da dormência em sementes de Brachiaria humidicola (Rendle) Schweickerdt. Científica, v. 14, n. 1/2, p. 65-72, 1986.

RUIZ, R. R.; SÁNCHEZ, O. M. S.; KELLER-GREIN, G. Rendimiento y calidad fisiologica de la semilla de Brachiaria spp. en los Llanos colombianos. Acta Agronomica, v. 46, n. 1/4, p. 23-29, 1996.

SIMPSON, G. M. Seed dormancy in grasses. Cambridge: Cambridge University Press, 297p. 1990. https://doi.org/10.1017/CBO9780511721816

USBERTI, R.; MARTINS, L. Sulphuric acid scarification effects on Brachiaria brizantha, $B$. humidicola and Panicum maximum seed dormancy release. Revista Brasileira de Sementes, Pelotas, v. 29, n. 2, p. 143-147, 2007. https://doi.org/10.1590/S0101-31222007000200020

VIEIRA, H. D.; SILVA, R. F. da; BARROS, R. S. Efeito de diferentes temperaturas sobre a dormência fisiológica de sementes de brachiarão (Brachiaria brizantha (Hochst. ex A. Rich.) Stapf). Revista Brasileira de Sementes, Brasília, v. 20, n. 2, p. 322-326, 1998. 